\title{
Review
}

\section{Figaro digital marketing - Conference review}

\section{Heat and chimp death do not deter delegates}

\section{Everything is different, not everything has changed}

\section{John Lewis embraces multi-channel}

\section{Unilever aims to help one billion improve their health}

Journal of Direct, Data and Digital Marketing Practice (2013) 15, 99-101. doi:10.1057/dddmp.2013.49

There was a great turnout for the Figaro Digital Marketing conference at the Royal College of Physicians in London considering the blazing heat wave taking place outside on 18 July. There seemed to be a flurry of activity for both presentation tracks, and even the news that Louis, the chimp from the PG Tips adverts, had sadly passed away the week before at the grand old age of 37 didn't seem to dampen spirits too much.

Sarah Mansfield, media director, Unilever UKI, who announced the sad news about Louis, also delivered an interesting session on 'The digitally empowered customer'. She explored how the customer journey has become more complex with multiple touchpoints, but was keen to point out that just because everything is different doesn't mean that everything has changed.

Consumers still want value and advice - it's just the approach to shopping that has changed. Research online, purchase offline is now a prominent trend and, more often than not, it's mobile that is the connection between on and offline. Equally, traditional channels are not dead, just more powerful when combined with online channels.

John Lewis was an example that Mansfield cited as fully embracing the multi-channel customer, once the retailer realised that a multi-channel customer was worth 3.3 times more to it than a pure store-only customer. Consequently, John Lewis has grown its base of multi-channel customers by 27 per cent since 2010 . This really demonstrates that it is talking to its customers at the right touchpoints where it is most relevant for the customer.

Mansfield also rightly stated that it's only the brands that think of things in a multi-channel environment that will be the true winners. Unilever has demonstrated its belief in getting its brands to the customer at the point of need with its 'power house' brands Flora and Persil. For the 'Persil Iconic' campaign, the 'i-mum' is the key audience, so Unilever talked to this group where it was most likely to engage and interact - mainly on the go through mobile phones.

It would be remiss of me not to cover Unilever's Sustainable Living Plan - sustainability is at the heart of what it does. As well as doubling the size of its business by 2020, the company also wants to reduce its environmental impact. It aims to help one billion people improve health and well-being, and wants to halve the environmental impact of its products and source 100 per cent of its raw materials sustainably. 


\section{Focus on evolution, rather than the future}

\section{Pizza Hut innovating through mobile}

\section{Organising for} customer insight

\section{Transport for London builds new digital service}

\section{Marketing practice lags behind on personalisation}

It's refreshing to see such clarity of vision and commitment from a large-scale corporate.

Rather than focusing on future vision, it was surprising how many sessions throughout the day focused on 'evolution'. I lost count of the number of times that I heard 'back in 2007' as if it was centuries ago - it's the rapid pace of technological change that justifies referring to 2007 as the 'olden days'.

Steve Ash, sales director, Pizza Hut UK, correctly observed that you can't shoehorn technologies of the past into the technology of the future. He took us through how Pizza Hut has effectively created a new business through fully integrating mobile into its system and now 30 per cent of its online orders come via mobile channels. He advised firms to challenge the thinking they've done in the past and do something new and exciting.

'Back in 2007', a mobile marketing strategy probably wasn't even on the radar, said Ash. Pizza Hut worked closely with SDL to overcome the major hurdles of achieving agility and keeping up with the rapid pace of change, from PCs to tablets to smartphones to wearable technology. Ash was keen to point out that the team at Pizza Hut was all too aware that company silos stifle progression and customers often end up in the middle when new processes are implemented. Hence, technology needs to be heavily integrated and not developed in silos, as Pizza Hut and SDL set out to do and successfully accomplished.

In order to embark upon the multi-channel 'revolution', many of the sessions went back to basics and advised the audience to start with deep customer insight. To do this successfully, businesses need to ensure that they first get the right teams (and organisational structure) in place. Throughout the day, there were many predictions that there will be massive demand for data scientists within the marketing industry. This is something that we have witnessed at the IDM and responded to with the launch and success of our Data Discovery Workshop earlier this year, encouraging graduates from all backgrounds to embark on careers in data.

It's evident that actionable insight drives many new technological developments and also allows for a greater degree of personalisation. Michael Campbell from Transport for London and Tim Hurles from We Are Experience took us through how they used customer insight to design and build a new digital public service for London. Through focus groups and storyboards, they decided on a 'mobile first' approach that was not just a cut-down version of the desktop experience, proving how they listened to their customers and focused on what benefits users wanted (rather than implementing a solution to suit the existing business structure). Next in the development pipeline is 'My TFL', demonstrating the commitment to personalisation.

John Watton from Silverpop further investigated the theme of personalisation, although he was quick to point out that marketing practice is 10 years behind the marketing vision. Marketing folk are not quite there yet with personalisation and are still at the segmented audience stage. The industry is currently trying to move from a 'bucketing approach' to 'segments of one'. 
The only way to move to the next stage is through obtaining a deep knowledge of customer behaviour, which needs to be extrinsic as well as intrinsic. The power of this knowledge then opens the gateway for organisations to create marketing messages that combine the customer's heart and mind by touching all of their emotional touchpoints (as covered in the brilliant session by Irisini Davis from Kyp London).

All in all, it was an insightful conference, covering interesting aspects of multi-channel marketing, which requires an evolution in practice that didn't exist 'back in 2007'. It won't be very long at all until we look back at 2013 and sneer at how once we viewed mobile as a separate channel with all the challenges that went with it.

Sheree Hellier 